\title{
Blended Learning in Research Statistics Course at The English Education Department of Borneo Tarakan University
}

\author{
https://doi.org/10.3991/ijet.v15i07.13231 \\ Ridwan $^{\varpi}$, Hariaty Hamid, Irianto Aras \\ Borneo Tarakan University, Tarakan,Indonesia \\ ridwan.fkipubtegmail.com
}

\begin{abstract}
The development of information technology that is very rapidly grown nowadays, particularly the development of information and communication technology enriches the development of the concept of learning based on blended learning. The characteristics of its apparatus, which can always be accessed anytime, anywhere, multiuser and offers all its simplicity have made blended learning as a medium of instruction which is very appropriate for the development of education. One of the courses considered essential to utilize the information and communication technology is a research statistics because the process of learning, this course has two fundamental parts which cannot be separated to one another, namely theory and practice. Thus, it needs a plan of learning activities which combine face-to-face learning and online-based learning interaction. The research was required to conduct to develop blended learning on research statistics course for the students of English Education Department of Teacher Training and Education Faculty of Borneo Tarakan University under a Research and Development by using the ADDIE's model. The evaluation which was conducted to find out validity, practicality, and effectiveness of blended learning drew three main conclusions: First, the design and development of learning devices were appropriate to be used as guidelines in implementing the learning process. Second, the process of learning was implemented in accordance with the plans and learning devices as well as a learning setting. Third, the students' learning achievement was classically completed. Thus, the blended learning was found to be valid, practical, and effective for the development of learning.
\end{abstract}

Keywords - Blended Learning, Online Learning, Learning Achievement

\section{Introduction}

We are in a unified world with exceptional access to a widespread pattern of online information and experiences. The world where excitement and opportunities are just a screen touch away [1]. This leads to the massive use of information and communication technologies in educational practices, which enhances drastic changes in the roles of educators and learners. It opens the way for new and innovative methods of teaching 
and learning which previously could only be done through traditional face to face classroom settings, and now it can be prepared by independent and distance learning using various computer-assisted media both offline and online.

The twenty-first century or often called the industrial revolution 4.0 demands to change how human activities take place in the scale, scope, complexity, and transformation of previous life experiences. Learning contents are expected to be able to meet these demands through various learning, innovation, critical thinking and problem solving, digital literacy skills, as well as career and life skills [2]. So, an educator must try to innovate learning to trail the actual conditions in encouraging students to grow according to their era.

One of the courses considered essential to utilize the information and communication technology is research statistics because the process of learning, research statistics has two fundamental parts which cannot be separated to one another, namely theory and practice. The theoretical aspects carried out in the face-to-face process have taken up quite a lot of lecturing hours, so that the practical elements involving students to analyze data through the application of data processing encounter some obstacles. On the other hand, synchronization between research method and data analysis techniques dealing with various kinds of research dynamics requires more time outside the learning hours, because different research methods or designs will make data analysis techniques also different. Thus, it needs a plan of learning activities which combines face-to-face learning and online-based learning interaction.

From the experience of the teaching team in handling the Research Statistics course at the English Language Education Department of Borneo Tarakan University, an essential aspect in a learning outcome is that the students are able to process and interpret research data as a provision in preparing the final project (thesis). However, the limitation of space, time, and learning facilities causes it to be very difficult to achieve. The complaint of the students is in the difficulty of understanding concepts, the statistical concepts if not taught through real examples and with the help of application will be complicated for non-mathematical students to understand. These various problems require the Research Statistics teaching team to find a new approach of teaching as alternative learning that can integrate traditional and contemporary aspects using media and the role of information technology in a series of learning activities. One solution that is considered to be able to overcome these problems is the implementation of blended learning by utilizing the e-learning at Borneo Tarakan University, which so far has not been exploited properly.

Blended learning systems is a combination of face-to-face instruction and online computer-mediated instruction [3]. The term "blended learning" [4] refers to the structure of a course and the approach to teaching and learning in which, generally $30 \%$ to $70 \%$ of the instruction is delivered online, with the remainder distributed in the classroom. Blended learning is recognized in teaching and learning circumstances where there is an effective combination of various modes of delivery, models of instruction and styles of learning as a result of adopting a strategic and systematic approach to the use of technology merged with the best features of face-to-face interaction (Krause in [5]). The mixing of face-to-face teaching and online learning enables students to have some choices over where they study (at school, at home, or somewhere in between) and 
when they study (during school hours, in the evening, or on weekends); but it is still the teacher who decides the extent of choice, as well as which elements of the student's learning are completed online and which elements are completed in the class.

These tremendous features of blended learning provide an optimal and exciting environment for teaching and learning that positively affect the process of knowledge acquisition as a whole. In this respect, Marsh in [6] remarks that blended learning has many advantages over the traditional mode of learning a language. To them, blended learning:

1. Provides more individualized learning experience

2. Provide more personalized learning support,

3. Support and encourage independent and collaborative learning among learners

4. Increase learner engagement in learning

5. Adapt many different learning styles

6. Provide a place to practice beyond the classroom

7. Provide a less stressful practice environment

8. Provide flexibility of studying to meet learners' needs

9. Help learners develop the necessary learning skills for the twenty-first.

The main target of using blended learning in this research is the use of information and communication technology in order to help students understand and apply the concepts being taught. This is very relevant to learning research statistics, where face-toface learning must be accompanied by data analysis tutorial using a program because data processing will, in fact, be very difficult if it is done manually. For this reason, the development of research statistics course through blended learning is expected to minimize the difficulties experienced by students majoring in English Education at the Faculty of Teacher Training and Education at Borneo Tarakan University.

\section{Method}

Research methodology provides an explanation of the techniques applied to collect the data, analysis, and present it in a logical manner [7]. This research was a research development that aimed at developing blended learning on Research Statistics course. The subject of this research was the fifth-semester students of Local B at English Education Department of Teacher Training and Education Faculty of Borneo Tarakan University who programed Research Statistics course. The research procedure used the ADDIE Model [7], which consists of five stages: analysis, design, development, implementation, and evaluation. The analysis stage includes analysis learning outcomes, learning resources, and students' condition and characteristics. The design stage consists of designing activities and learning devices. The development phase is the process of embodying the design results on a pattern and learning activities. The implementation stage is the process of applying the results of design and development into learning activities. Last, the evaluation stage is to know whether or not the process of instruction meets the criteria of quality. 
The quality criteria used in this research was the quality criteria for a product by [8], which consists of validity, practicality, and effectiveness. To collect the data, some instruments were used in the form of validation sheet, observation sheet, questionnaire, and achievement test. Research data were analyzed quantitatively and qualitatively. Qualitative analysis was used to describe the results of the development, quantitative analysis related to the presentation of data resulting from validation, observation, questionnaire, and achievement test.

\section{$3 \quad$ Result and Discussion}

The process of development used five stages of the ADDIE Model: analysis, design, development, implementation, and evaluation as presented as follows.

\subsection{Analysis stage}

Analysis is the first stage that must be determined by the instructional developer. At this stage, the main activity is to analyze:

1. Learning outcomes

2. Learning resources

3. Students' condition and characteristics.

First, the learning outcomes that have been proposed in the curriculum are that the students are expected to be able to:

a. Explain the nature of statistics

b. Present the data into tables and diagrams

c. Determine the scoring system, central tendency, location, and dispersion

d. Determine the research sampling technique

e. Apply the research data analysis using descriptive procedure

f. Interpret the hypothesis testing.

Second, learning resources as a consideration in developing learning materials and activities. Those can be resources that are utilized and are designed. In this case, the learning resources that can be utilized are the existing facilities available at Borneo Tarakan University, and those that are designed are the learning materials arranged by the team of research statistics subject.

Last, the students' condition and characteristics. Based on the observation and interview to students, it was obtained several things as follows:

1. The age of students ranged from 20-24 years old in which it is accordance with the theory of developmental psychology categorized as adults, meant that students can think abstractly

2. The completeness of technology and information tools which is already owned by every student. Out of 35 students, there was only one student who did not have laptop and all of them had smartphones 
3. The students' prior knowledge of Research Statistics is still trifling

4. The students have already done e-learning, but only a few meetings due to the unstable campus network

5. The students' GPA are varied within high, medium, and low ability.

Based on this condition, blended learning can be applied by utilizing a smartphone or laptop with the help of lecturer as a facilitator. The ability gap among students can be overcome by grouping them through cooperative learning, but independent learning is also emphasized, especially in working with the assignments.

\subsection{Design stage}

This stage is basically a decision-making process. Designing is based on what has been formulated in the analysis stage. This is an analogue to syllabus making. It includes designing the learning/instructional materials, determining the learning strategies, designing learning devices, and creating e-learning class forum.

a. Designing the learning materials: Based on the learning outcomes that had been formulated in the analysis stage, the materials were then designed and/or selected by considering the hierarchy of learning materials, either procedurally or conceptually.

b. Determining the learning strategies: Learning strategies are related to what tactics are used in conveying the learning materials. The learning strategy is also determined based on the analysis in the early stage. This strategy is concerning with the learning models, approaches, methods, and media.

1. Learning model:The way of students' learning in general was by using e-learning. In order to make learning activities more organized and directed through a syntax, several learning models were applied. They were direct instruction, cooperative learning, problem based learning, and project based learning.

2. Learning approach: The learning approach used was a contextual approach and problem solving. The contextual approach was used to raise contextual problems that existed around students that were solved by using statistics, while the problem solving approach was used to direct students to solve problems independently or in groups.

3. Learning method: The learning method used was the expository, discussion, question and answer, and guided discovery. This is adjusted to the model and approach used in the learning design.

4. Learning media: The learning media used was e-learning media. The e-learning page included the course name, course description, and materials (pdf, PPT slides, URL links: videos and websites), and assignments.

c. Designing learning devices: The initial draft of the learning tool to be developed was based on the results of a discussion with the team teaching. Learning devices include the lesson plan, modules, presentation slides, and learning instruments.

d. Creating e-learning forum: The design of e-learning forum that was made was firstly communicated with the head of the ICT Center of Borneo Tarakan University. The main features available on the e-learning page are course management in 
the form of course description, addition of learning resources, addition of learning activity, and division of groups. The additional features are private files, new questions, question banks, import activities, YouTube links, and messages. Out of those features, the e-learning design made in this course was referred to the main points of learning and was made as practical as possible. The features used were resources, activity, group, youtube/web links, and question banks.

\subsection{Development stage}

This is the stage of production where everything that has been made in the stages of design can be manifested, and it was carried out as described as follows.

a. Development of learning materials: Learning materials that had been determined at the design stage were then developed into an instructional module regarding with the learning outcomes and learning objectives. The module consisted of several materials that were discussed during lecturing. Although it was fully arranged for one semester, the delivery of materials to students was given one by one through the e-learning page in pdf format. It aimed at making students more focused on a learning goal.

b. Development of learning strategies: The design of learning strategies was then developed into a series of learning activities. Based on the analysis, the decisions about how to teach students varied for each meeting. For the first two meetings, full online was conducted by giving students materials in pdf format, URL links, and videos. Furthermore, the students were directed to provide comments or questions through the discussion forum that had been provided. This was done because the content of the materials in the first two meetings was not too complicated to be followed and studied independently by students. Meetings 3-7 were conducted more varied through face to face by accessing the materials online with a diverse proportion, either $25 \%$ for face to face learning, $75 \%$ for individual learning or in groups through e-learning or vice versa. For meetings 9-15 (meeting 8 for mid-test and meeting 16 for final test) in which materials referred to the SPSS-assisted data analysis, the proportion of face-to-face learning was more directly enlarged using an offline computer.

c. Development of learning devices:To support the learning process, the Research Statistics elements from the planning to the evaluation process were outlined in the learning devices in the form of

1. Lesson plan

2. Module

3. Student worksheet

4. Powerpoint slides.

The data analysis tutorial that was planned previously was considered to be included in the module. 
1. Lesson plan:The lesson plan was made by the team based on preliminary analysis. Basically, the lesson plan was different for each meeting adjusting to the difficulty level of learning materials. If it was considered easy, the students were then directed to independent learning, but if it was considered difficult, the faceto-face process was more taken by providing enough guidance.

2. Module: The presentation of Research Statistics materials was designed in the form of a textbook that was used for 16 meetings.

3. Student worksheet: Student worksheet was made and provided in the e-learning page. The worksheet was called "assignment" which contained problems to be solved by the students done individually or in groups as the process of exploring concepts. The assignment was given in each meeting in order the students understood the concept or procedure through the process of experiencing.

4. Powerpoint slides: The presentation slides became more important in which the students could grasp the general key points of the learning materials. The presentation slides were in the form of a ppt file. Due to difficulties (excessive capacity) in uploading them to the e-learning page, the slides were firstly converted to pdf format.

5. Instruments: To obtain data about the process of learning through blended learning, the instruments needed to be prepared. Those instruments consisted of the achievement test, questionnaire, and observation sheet. The achievement test was given in the mid-term and final-term to see the students' learning results. A questionnaire was given to see the students' responses toward learning activity, the use of module, worksheet, and lecturer competence. And observation sheet was used to check the students' learning activity during the process of learning through blended learning.

d. Creating an e-learning discussion forum: After communicating with the ICT centre of Borneo Tarakan University, the ICT staff then made an e-learning account where the Research Statistics team could start creating a learning management system. As stated earlier, the features that were utilized in the UBT elearning page were resources, activity, group, youtube/web links, and question banks.

\subsection{Implementation stage}

The learning system is ready to use on this stage. It aims at implementing the model of blended learning.

a. First meeting: The first meeting of the Research Statistics subject was held on 8th September 2018. The focus of learning material was to explain the syllabus (RPS) and learning contract. The process of learning was carried out in full online without any face-to-face activities. This was done because the teaching team was outside of Tarakan and the content of the material at this initial meeting was still introductory and theoretical. During lecturing hours, the students were directed to log in to e-learning class which had been prepared by giving a comment "present" on the chat form. After that, the lecturer asked them to open 
the video link then to give comments or responses around the academic rules, learning materials, and learning contract.

b. Second meeting: The second meeting was held on 15th September 2018. The function of statistics in research was introduced through online. At the second meeting, the students were expected to log in during the lecturing hours to access the learning material (module), presentation slides, and learning video. The discussion forum was also prepared to respond to the students' questions. After being given time to study the materials, the students were then given a task that has been prepared on the e-learning page.

c. Third meeting: The third meeting was held on 22nd September 2018 focusing on the type of data, data presentation, measurement scale, and frequency distribution. The process of learning was carried out in a combination of online and face-to-face learning. The learning was started by conveying the learning objectives and directing students to open the e-learning page. The core activities were in the form of students discussion related to the learning topic, sharing among groups, and closing activity was by giving quizz. During the learning activities, the lecturer carried out his function as a learning facilitator and let the students create their own ways of learning. The students were also asked to use their mobile phone to explore learning materials on the e-learning website.

d. Fourth meeting: The fourth meeting was held on 29th September 2018 with the learning material on the central tendency. The process of learning was carried out similar to the third meeting which was a combination of online learning and face-to-face learning. The learning was begun by conveying the learning objectives and directing students to open the e-learning page. The core activity was in the form of problem solving (via e-learning page) where the students worked in groups and made a presentation. The closing activity was in the form of providing a conclusion relating to the material discussed. The role of the lecturer as a facilitator who was ready to facilitate/guide the groups needed for clarification or explanation pertaining to the materials being learned.

e. Fifth meeting: The fifth meeting was held on 6th September 2018. The learning material was about dispersion. The process of learning was the same as the process in the third and fourth meeting in which there was a combination of online learning and face-to-face learning. It was just that for the fifth meeting, the online learning process was given in a smaller portion than the previous meetings. It was replaced by the use of an offline computer. The lecturer began the lesson by conveying the learning objectives and directing the students to open the e-learning page to access the material provided. In the core activity, the students in groups were directed to the UBT library and followed the procedures (project-based) that had been uploaded on the e-learning page to treasure the research data. The research data were firstly analyzed manually to find out the variances and standard deviations. After that, the analyses were by using SPSS to adjust the results with that of manual calculation.

f. Sixth meeting: The sixth meeting was held on 13th October 2018. The learning material focussed on sampling techniques. The learning process was carried out the same as that of in the third and fourth meeting, namely the integration of 
online learning and face-to-face learning. The learning objectives were introduced by the lecturer and let the students open e-learning page to access the material that had been provided. The core activity was in the form of group discussion relating to given topics, exchanged group members, but did quiz individually. The lecturer role during the learning activity was a learning facilitator

g. Seventh meeting: The seventh meeting was held on 20th October 2018 focusing on the method of data analysis. The learning process was exactly the same as that of in the sixth meeting, namely the integration of online learning and face-to-face learning. The core activity was in the form of group discussion, exchanged group members, and did quiz individually. At the end of the lesson, the students under the guidance of the lecturer summarized the learning materials. The students were also required to prepare themselves for the mid-test in the following week.

h. Eighth meeting: The eighth meeting was held on 24th October 2018. This meeting was merely regarding to the evaluation. The evaluation was conducted to measure the students learning outcomes during the first half period of the semester and their responses toward the learning activity through blended learning. The students were given an achievement test as the mid-test and a questionnaire.

\subsection{Evaluation stage}

a. Validity: Based on the results of experts validation of the learning devices, it was obtained a summary of experts validation as presented in Table 1.

Table 1. Summary of experts validation

\begin{tabular}{|l|l|l|}
\hline \multicolumn{1}{|c|}{ Learning devices } & \multicolumn{1}{c|}{ Mean } & \multicolumn{1}{c|}{ Criteria } \\
\hline Lesson plan & 3.77 & Very Valid \\
\hline Instructional module & 3.62 & Very Valid \\
\hline Student worksheet & 3.87 & Very Valid \\
\hline Achievement test & 3.75 & Very Valid \\
\hline
\end{tabular}

Based on Table 1, it can be concluded that the mean score of validation results from the experts on the design of learning devices - lesson plan, instructional module, student worksheet, and achievement test-fell into "very valid" category. This means that the learning devices had met the valid criteria and ready to use. In other words, the learning devices were well made. However, according to the experts, the results of the design were still needed to have minor revisions. The revisions that had been made are as follows:

1. Revision on student worksheets covered: (a) correction on the questions that were considered ambiguous, and (b) adding specific instruction on how to do with the worksheet in each meeting. 
2. Revision on lesson plans. The improvement needed to make were the learning materials and learning steps on each lesson plan which should be adjusted to the flow of the materials in the instructional module.

3. Revision on the instructional module was by adding a variety of problems which could stimulate the students to carry out activities according to the learning patterns.

4. Revision on achievement test was on the words/phrases/sentences which were considered ambiguous that made students difficult to understand.

b. Practicality: Practicality is seen in two aspects: the feasibility of learning devices and the implementation of the learning devices. First, the feasibility of learning devices. The results of experts validation that the learning devices could be used as the result of the feasibility of learning. Overall, the degree of feasibility was in "quite valid" category. This indicates that the learning design was adequate to use. Second, the implementation of the learning devices. The process of learning could be said "implemented", if every meeting the lecturer could conduct the learning steps in accordance with the planned steps (lesson plan) categorized as "quite good". The data collected from the observation sheet in six face-to-face meetings were found that the ability of the lecturer in implementing the learning process was "quite good". Based on data resulting from the feasibility of learning devices validated by the experts and the ability of lecturer in implementing the learning process obtained from the observation could be said that blended learning had met the practicality criteria.

c. Effectiveness: Effectiveness can be seen from three aspects, namely: students' activities, students' questionnaire responses, and students' achievement test. Firstly, the students' activities based on observation were obtained that their activities in the learning process were in "quite active" category. Thus, it can be said that the students' activities had met the specified criteria. Secondly, the students' responses to the learning process, instructional material (module), worksheet, and the ability of the lecturer were obtained the results that $77.14 \%$ (positive category) of the students responded positively to each item of each aspect of the questionnaire. It can be said that learning process through blended learning was very helpful to foster the students' participation and comprehension. Finally, the achievement test shows that the students gained the mean score 77.03 with a standard deviation of 4.66 , minimum score 63.8 , and maximum score of 80.7 . The classical learning mastery achieved by the students was $85.71 \%$ in which it was above 65 (as criteria of completeness) of the ideal score of 100 . Thus, the students' learning outcome was achieved. It can be concluded that all aspects of learning effectiveness: students' activities, students' questionnaire responses, and students' achievement test had met the criteria of "effectiveness".

Research on the development of a learning model and its application has obtained findings that indicate the effectiveness of students' learning needs in increasing their learning independence. Therefore, the blended learning development has implications 
both theoretically in adding to the treasury of knowledge, as well as practically for operational policies that can be applied in the implementation of learning.

The aim of this research is to develop a learning model based on blended learning by utilizing the Borneo Tarakan University e-learning platform on Research Statistics course. This research has resulted in what is called a blended learning model which includes a syllabus (RPS), lesson plan, instructional module, student worksheet, achievement test and learning products in the forms of pdf files, PowerPoints, and videos uploaded on the e-learning platform of Borneo Tarakan University. Blended learning is one of the revolutions in the field of internet technology-based education that can be used as a support for learning. In its implementation, utilizing blended learning through internet technology does not require learning by using online only, but the implementation of learning must still be combined with face-to-face instruction.

Findings from the students' responses show that they would value a blended learning approach. They were ready to try something new and considered it helpful, interesting, and motivating to perform the tasks and stimulated practical works. These results are consistent with the prior research showing that students learned much better online medium which was particularly useful for making the coursework accessible, flexibly learnable and teachable, making it more student-centered rather than teacher-based [10]; [11]; and [12].

Designing a blended course also improves students' learning achievement and their participation in the implementation of such a blend. O'Toole and Absalom in [13] state that uploading material online positively affects the achievement level of the students. It is observed that the students who read the online course materials besides the in-class lecture had got better performance in a quiz or in an exam than those who only depended on the in-class regular lecture. Also, the blended materials allow the students to learn according to their own speed of learning. This matches to Tomlinson and Whittaker in [14] who state that students can study when they want and at any speed; and this is also consistent with [4] who says that the students have more control over the timing, pace, place, and path of their learning. It leads to student-to-student collaboration and sharing, and student and instructor communication.

The role of instructors in blended learning is no longer at the center of direct content delivery. It shifts [15] to student-centered instruction in which students become active and interactive learners. The instructor becomes a facilitator who provides the content framework, information resources, and one-on-one support or group-learning tasks and solve problems. To do so, [16] suggest that instructor must be effective and be an active participant in the classroom, observing, analyzing, and interpreting information about student learning and then using this information for planning and decision making.

\section{Conclusion}

The development of blended learning on Research Statistics course for the students of English Education Department of Teacher Training and Education Faculty of Borneo Tarakan University can be drawn three main conclusions as follows: First, the design 
and development of learning devices (lesson plan, instructional module, student worksheet, and achievement test) were appropriate to be used as guidelines in implementing the learning process. Second, the process of learning was implemented in accordance with the plans and learning devices as well as a learning setting. The learning illustrates the process of varied learning materials and learning strategies provided in both online and offline environments. Third, the students' learning achievement was classically completed. The students were found to receive the blended learning model positively and participate fair actively. They considered such a blend useful and helpful for the improvement of their understanding.

Overall, blended learning was found to be valid, practical, and effective for the development of learning. Therefore, the implementation of the blended learning model can be used as a supplement face-to-face learning activities with the access to online learning, completing the delivery of instructional materials in a wide range of theoretical and practical competencies, and systematic combination of face-to-face and online learning to build the construction students' ideas.

\section{$5 \quad$ References}

[1] Watterston, Jim. 2012. Blended learning. A synthesis of research findings in Victorian education 2006-2011. Melbourne: Ultranet and Digital Learning.

[2] Trilling, B \& Fadel, C. 2009. 21st Century Skills: learning for life in our times. US: JosseyBass A Willey Imprint

[3] Bonk, Curtis J., \& Graham, Charles R. 2006. The handbook of blended learning: Global perspectives, local designs. San Francisco: Pfeiffer.

[4] Kossy, Judith. 2017. Blended Learning Tool Kit. New York: UnidosUS.

[5] Bath, Debra and Bourke, John. 2010. Getting Starter with Blended Learning. Queensland, Australia: Griffith University

[6] Kashghari, Bahiya and Asseel, Dalia. Collaboration and Interactivity in EFL Learning via Blackboard Collaborate: A Pilot Study. International Conference ICT for Language Learning. Conference Proceedings. 7th Edition. 2014;149-154.

[7] Creswell, John. 2009. Research Design: Qualitative, Quantitative, and Mixed Methods Approaches. Third Edition. Thousand Oaks, California: Sage Publications, Inc.

[8] Pribadi, Benny A. 2009. Model Desain Sistem Pembelajaran. Jakarta: Dian Rakyat.

[9] Nieveen, Nienke. 1999. Formative Evaluation in Eduacational Design Research. In Tjeerd Plomp \& Nienke Nieveen (Eds). An Introduction of Educational Design Research. Netzodruk, Enschede, SLO. 2007;89-102.

[10] Jung, Rosa and Lee, Chung Hyun. Using Internet video clips for university

[11] students' vocabulary development in blended learning. Multimedia-Assisted Language Learning. 2013;16(4):67-96. https://doi.org/10.15702/mall.2013.16.4.67

[12] Al-Jabry, Hamdy; Salahuddin, Mohammed; Al-Shazly, Abdul-Latif. Developing and Piloting a Literature Course Learnable Via Blackboard for EFL Literature Instruction. Studies in Literature and Language. 2014;8(1):85-95

[13] Ju, Suo Yan and Mei, Suo Yan. Perceptions and Practices of Blended Learning in Foreign Language teaching at USIM. European Journal of Social Sciences Education and Research. 2018:12(1):170-176 https://doi.org/10.26417/ejser.v12i1.p170-176 
[14] Mofrad, Esmail Zainadiny. Enhancing EFL Learners' Writing Capability in a Blended Learning Environment: The Effects of Learning Styles. International Journal of English Language \& Translation Studies. 2017;5(3):201-209

[15] Qindah, Suzan. The Effects of Blended Learning on EFL Students' Usage of Grammar in Context. The Eurasia Proceedings of Educational \& Social Sciences (EPESS). 2018;10:1122

[16] Dziuban, Charles D.; Hartman, Joel L.; Moskal, Patsy D. Blended Learning. EDUCAUSE Center for Applied Research. Bulletin. 2004;7:1-12.

\section{Authors}

Ridwan is a lecturer in English Education Department of Teacher Training and Education Faculty of Borneo Tarakan University. His research interests are blended learning and English language teaching. Email: ridwan.fkipubt@gmail.com

Hariaty Hamid is one of the lecturers in Mathematics Education Department of Teacher Training and Education Faculty of Borneo Tarakan University. Her primary interest is in mathematics teaching and learning. Email: hariaty.pmat@gmail.com

Irianto Aras is a primary education lecturer in Teacher Training and Education Faculty of Borneo Tarakan University. His research interest is mathematics instruction in primary education. Email: arasirianto1990@gmail.com

Article submitted 16 October 2017. Published as resubmitted by the authors 29 November 2017. 